\title{
Microsurgical training model with nonliving swine head. Alternative for neurosurgical education ${ }^{1}$
}

\author{
Lucas Alves Aurich', Luis Fernando Moura da Silva Junior", Felipe Marques do Rego Monteiro ${ }^{\mathrm{III}}$, Alexandre Nascimento \\ Ottoni $^{\text {IV }}$, Gustavo Simiano Jung ${ }^{\mathrm{IV}}$, Ricardo Raminav
}

DOI: $h$ ttp://dx.doi.org/10.1590/S0102-86502014000600010

\begin{abstract}
IMD, Neurosurgeon, Department of Neurosurgery, Neurological Institute of Curitiba (INC), Curitiba-PR, Brazil. Conception, design, intellectual and scientific content of the study, manuscript writing.

IIMD, Neurosurgeon, INC, Curitiba-PR, Brazil. Intellectual and scientific content of the study, critical revision.

IIIMD, Neurosurgery Resident, INC, Curitiba-PR, Brazil. Conception and design of the study, acquisition of data.



${ }^{\vee} \mathrm{PhD}$, Head, Neurosurgical Department, INC, Curitiba-PR, Brazil. Critical revision, final approval of the version to be published.
\end{abstract}

\section{ABSTRACT}

PURPOSE: This paper proposes a practical model of microneurosurgical training using a nonliving swine head.

METHODS: Fresh porcine heads were obtained from butchery and dissected at our Laboratory of Microsurgery. Brain and skull base surgery were trained under microscopic magnification.

RESULTS: Several neurosurgical procedures could be simulated in the nonliving pig model, including transcallosal approach to the lateral ventricle, lateral sulcus and middle fossa dissection, and posterior fossa surgery.

CONCLUSION: The swine model perfectly simulates standard microneurosurgical procedures, and is a useful tool for developing and refining surgical skills.

Key words: Neurosurgery, Microsurgery. Training. Models, Anatomic. Swine. 


\section{Introduction}

Laboratory training models are essential for developing and refining surgical skills. In addition to the improvement of technical proficiency, it provides a way to reduce risks to the patients. Ideally, the mastery of surgical techniques should be obtained first in the laboratory before being used in clinical practice $^{1,2}$.

Historically, several animal models were employed in order to provide surgical training. However, increasing sensitivity toward ethical aspects, strict legislation, and a greater public awareness, strongly require a significant decrease in using live animal models ${ }^{3}$.

Several training models were described in literature in order to reduce the use of live animals for surgical education ${ }^{3-6}$. As a result, nonliving animal tissues has become increasingly attractive on a cost basis, and these models are "closer-to-real-life" scenario compared to the prosthetic models, such as gloves and silicone tubes.

Swine has been used as a model of surgical training such as neurolysis and microvascular suture techniques with pig foreleg, and coronary arteries anastomosis with porcine heart ${ }^{3}$. In neuroscience the pig model was also used due to its similarities with the human brain ${ }^{7}$. Some authors have described an in vivo swine model for training neurosurgical residents ${ }^{8}$.

In view of the need of refining surgical skills and of reduce the use of live animals this paper suggests a practical model of neurosurgical training using a nonliving pig head.

\section{Methods}

Fresh swine heads were obtained from local butchery at a relatively low cost (US\$ 5.00/each) (Figure 1A). The head was kept in a refrigerator at $4{ }^{\circ} \mathrm{C}$ for six hours after it was slaughtered. Then, at our Laboratory of Microsurgery at Neurological Institute of Curitiba, was performed skin incision (Figure 1B), temporal muscle dissection (Figure 1C), and large craniotomy, with care taken to preserve the underlying dura (Figure 1D).

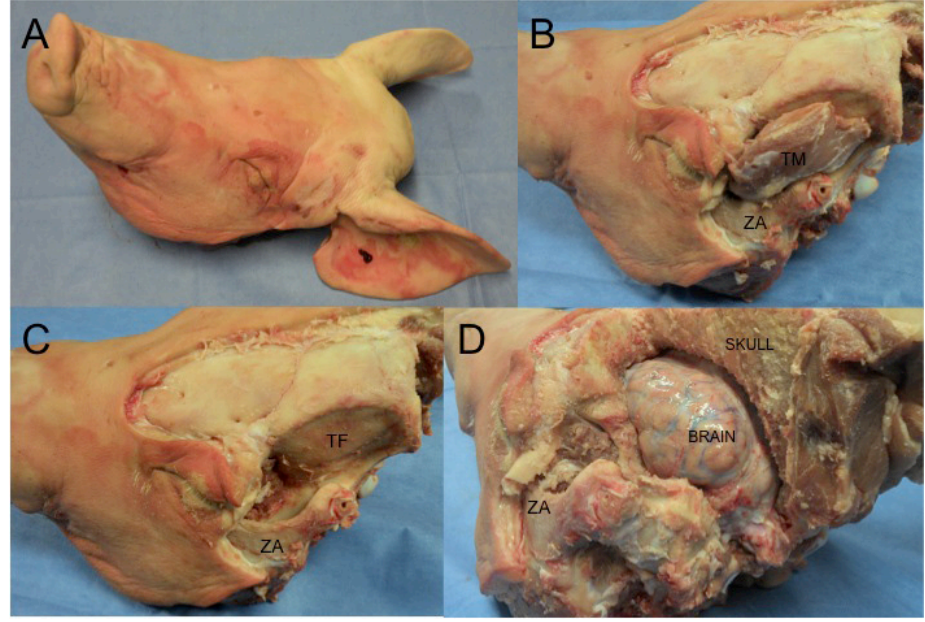

FIGURE 1 - Swine head preparation. ZA: zigomatic arc. TM: temporal muscle. TF: temporal fossa.

Brain and skull base surgery under microscope magnification were first simulated using fresh specimens. Subsequently, the porcine heads were embedded in formaldehyde $10 \%$ solution in order to increase the durability of the specimens.

Neurosurgical training steps were performed in an operating microscope (OpMi Zeiss Inc., Germany) with the use of microsurgical instruments, suction tube and drill (Figure 2). After craniotomy, an extensive dural open was performed exposing the supratentorial and infratentorial structures (Figure 3).

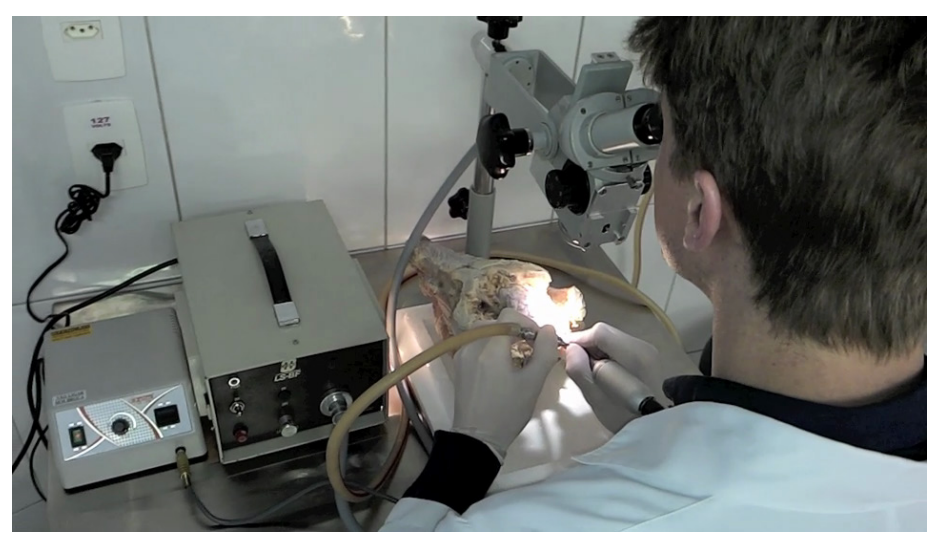

FIGURE 2 - Surgical instruments. 


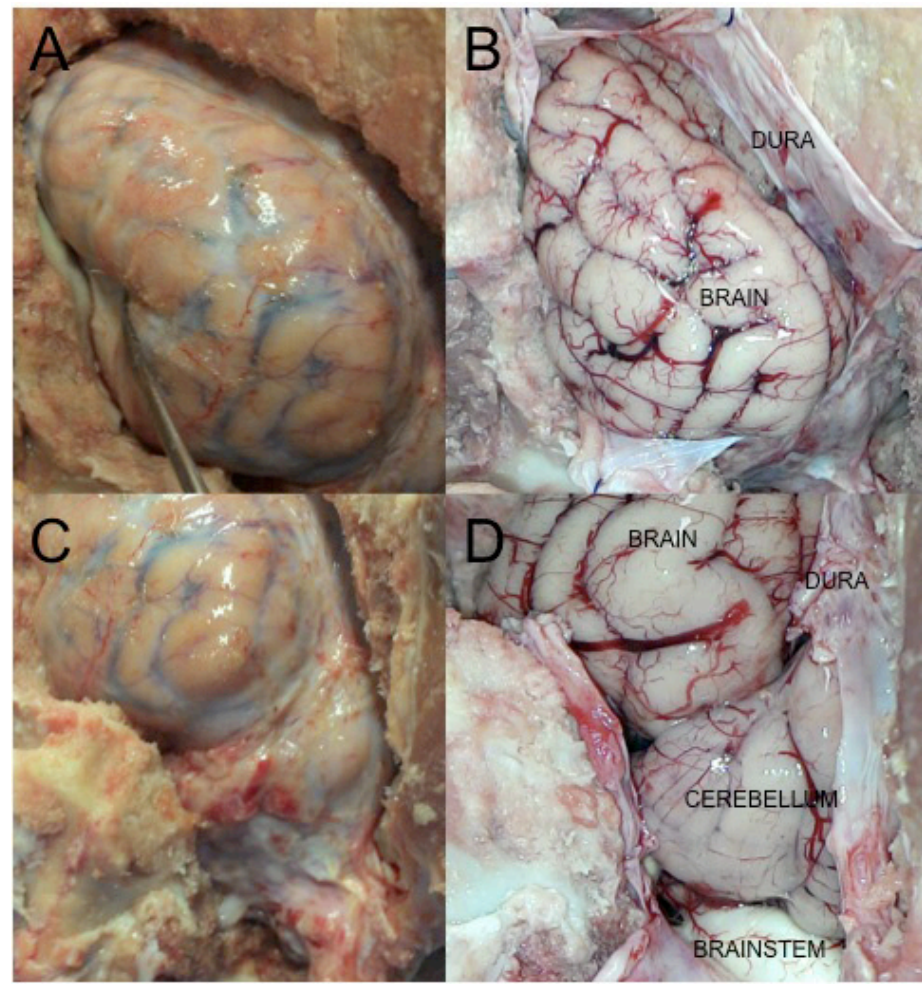

FIGURE 3 - Dura mater opening and brain exposition.

\section{Results}

Several microneurosurgical procedures could be performed in the nonliving pig model. At first, interhemispheric fissure was dissected to visualize cingulated gyri, callosomarginal and pericallosal arteries. In the sequence, a transcallosal approach to the lateral ventricle and to the area of the foramen of Monroe could be accomplished (Figure 4).

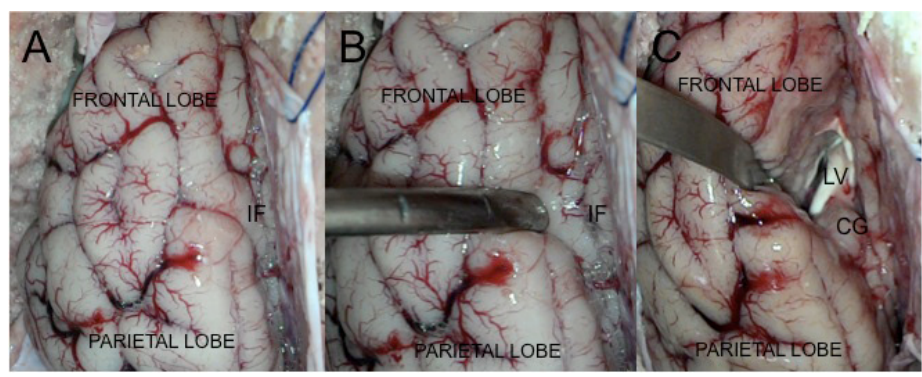

FIGURE 4 - Steps of transcallosal approach to the lateral ventricle. IF: interhemispheric fissure. CG: cingulated gyri. LV: lateral ventricle.

Middle meningeal artery, and V2 and V3 branches of trigeminal nerve was reached through extradural dissection of middle fossa (Figure 5A); and lateral sulcus was dissected in order to visualize optic nerve and internal carotid artery (Figure 5B and 5C).



FIGURE 5 - Middle fossa and lateral sulcus dissection. MMA: middle meningeal artery. LS: lateral sulcus. ICA: internal carotid artery. ON: optic nerve.

Forth ventricle and cranial nerves were dissected and visualized at the brainstem (Figure 6A and 6B). The cerebellum was partially resected to expose the cerebellopontine angle (Figure 6C). Drilling of internal auditory canal could also be accomplished.

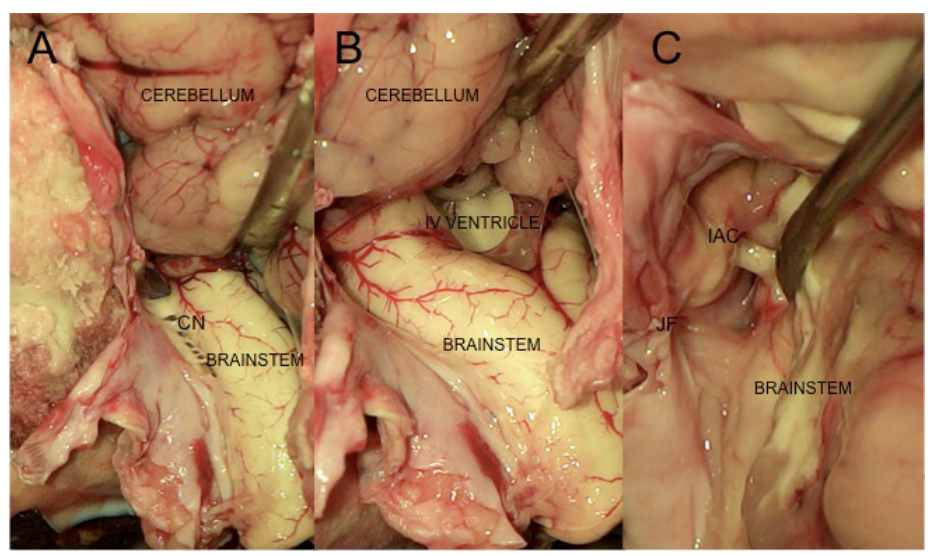

FIGURE 6 - Posterior fossa surgery training. CN: cranial nerves. ICA: internal auditory canal. JF: jugular foramen.

\section{Discussion}

Surgical residents may take years to master their required surgical skills, and laboratory training models are fundamental for this essential development before clinical application. Yarsargil advised young neurosurgeons to spend at least one year in a laboratory setting, training in surgical anatomy and microsurgical technique ${ }^{2}$.

A review in the literature depicts several models described for surgical education, including human cadaveric specimens $^{6}$, resected human tissues ${ }^{9}$, live animals ${ }^{10}$, synthetic 
materials, and nonliving animals. The main disadvantages of using human cadavers are the cost and the difficulty associated to the obtainment. Also, significant reduction in live animals training was expected due to strict legislation, a major public awareness, and an increasing sensitivity toward ethical aspects ${ }^{3}$.

Nonliving animals models are readily available at low cost and have been proposed as an alternative to prevent animal deaths. Nonliving animals may also mimic human anatomy and are more realistic comparing to synthetic materials, especially with fresh specimens usage. The major disadvantage of the model is the lack of a dynamic circulation ${ }^{11}$.

Achar et $a .^{5}$ proposed an interesting model of vascular anastomosis training using esophagus and trachea of nonliving chicken. Hino described a training exercise for microarterial anastomosis using a chicken wing artery ${ }^{12}$. These methods proved to be useful for learning microsurgical techniques and several advantages can be noted, including low cost and easiness to handle.

Neurosurgical training with nonliving animals were also reported. Hicdonmez et al. ${ }^{13}$ described a laboratory training model with fresh cadaveric cow cranium, simulating standard microneurosurgical steps in interhemispheric-transcallosal approach to the lateral ventricle. The same authors also designed a training model in cadaveric sheep cranium, mimicking the steps of posterior fossa surgery in humans ${ }^{14}$. Both methods proved to be useful to refine skills and to provide more intimate knowledge on brain surgery to the neurosurgery residents. In our study, both procedures could be accomplished in the swine brain model.

Pig brain is comparable to human one in gross anatomy, histology and vascularization with some differences. The frontal lobe is less developed and the olfactory system occupies a large portion of the anterior part of the brain. A massive skull protects its brain with size and shape changes during the growth resulting in surgical intervention difficult ${ }^{7}$. The weight of the adult pig brain ranges from 80 to $180 \mathrm{~g}$, and can be comparable to the brain mass of several non-human primate species used for experimental purposes ${ }^{15}$. Therefore, it seems to be large enough to allow neurosurgical training.

Regelsberger et al. ${ }^{8}$ published a 4-years experience in an in vivo swine model for training neurosurgical residents. Surgical procedures included craniotomy, dural opening, brain surgery and excision of an artificial tumor created by injection of colored fibrin glue. The model has proved to be a great opportunity for young neurosurgeons to train bleeding management and surgical complications.

Olabe et al. ${ }^{16}$ developed a reproducible technique for aneurysm creation in domestic swine and adapted it to mimic intracranial dissection in an in vivo model. Several aneurysm clipping techniques, emergency rupture situations and vascular reconstruction procedures could be trained.

Borucki et al. ${ }^{17}$ evaluated the endoscopic anatomy of the cerebellopontine angle through the retrosigmoid approach in a swine specimen, and found analogy to human's anatomy. In our study, the cerebellopontine angle was exposed and drilling of the internal auditory canal, an important step in vestibular schwannoma surgery, could be accomplished.

\section{Conclusion}

The pig model provides an alternative and has great value for the acquisition and refinement of surgical skills. In addition, this model contributes to the reduction of live animals usage for surgical training

\section{References}

1. Martins PN, Montero EF. Basic microsurgery training: comments and proposal. Acta Cir Bras. 2007 Jan-Feb;22(1):79-81. PubMed PMID: 17293955.

2. Yasargil MG. From the microsurgical laboratory to the operation theatre. Acta Neurochir (Wien). 2005 May;147(5):465-8. PubMed PMID: 15821999.

3. Schöffl H, Froschauer SM, Dunst KM, Hager D, Kwasny O, Huemer GM. Strategies for the reduction of live animal use in microsurgical training and education. Altern Lab Anim. 2008 May;36(2):153-60. PubMed PMID: 18522483.

4. Pessoa BBGP, Pessoa SGP. Treinamento em microanastomoses utilizando tubos de látex. Acta Cir. Bras. 2002;17(2):143-6. doi: org/10.1590/S0102-86502002000200010.

5. Achar RA, Lozano PA, Achar BN, Pereira Filho GV, Achar E. Experimental model for learning in vascular surgery and microsurgery: esophagus and trachea of chicken. Acta Cir Bras. 2011 Apr;26(2):101-6. doi: org/10.1590/S0102-86502011000200005.

6. Aboud E, Suarez CE, Al-Mefty O, Yasargil MG. New alternative to animal models for surgical training. Altern Lab Anim. 2004 Jun;32 Suppl 1B:501-7. PubMed PMID: 23581125.

7. Sauleau P, Lapouble E, Val-Laillet D, Malbert CH. The pig model in brain imaging and neurosurgery. Animal. 2009 Aug;3(8):1138-51. doi: org/10.1017/S1751731109004649.

8. Regelsberger J, Heese O, Horn P, Kirsch M, Eicker S, Sabel M, Westphal M. Training microneurosurgery - four years experiences with an in vivo model. Cent Eur Neurosurg. 2011 Nov;72(4):192-5. doi: org/10.1055/S-0030-1261906.

9. Romero FR, Fernandes ST, Chaddad-Neto F, Ramos JG, Campos JM, Oliveira Ed. Microsurgical techniques using human placenta. Arq Neuropsiquiatr. 2008 Dec;66(4):876-8. doi: org/10.1590/ S0004-282X2008000600019.

10. Schanaider A, Silva PC. The use of experimental animals in surgery. Acta Cir Bras. 2004;19(4):441-7. doi: org/10.1590/S010286502004000400014.

11. Aboud E, Al-Mefty O, Yaşargil MG. New laboratory model for neurosurgical training that simulates live surgery. J Neurosurg. 2002 Dec;97(6):1367-72. PubMed PMID: 12507135.

12. Hino A. Training in microvascular surgery using a chicken wing 
artery. Neurosurgery. 2003 Jun;52(6):1495-7. PubMed PMID: 12762899 .

13. Hicdonmez T, Hamamcioglu MK, Parsak T, Cukur Z, Cobanoglu S. A laboratory training model for interhemispheric-transcallosal approach to the lateral ventricle. Neurosurg Rev. 2006 Apr;29(2):15962. PubMed PMID: 12762899.

14. Tufan H, Baris B, Mehmet T, Turgay P, Sebahattin C. Posterior fossa approach: microneurosurgical training model in cadaveric sheep. Turkish Neurosurg. 2006;16(3):111-4.

15. Lind NM, Moustgaard A, Jelsing J, Vajta G, Cumming P, Hansen AK. The use of pigs in neuroscience: modeling brain disorders. Neurosci Biobehav Rev. 2007;31(5):728-51. PubMed PMID: 1744589 .

16. Olabe J, Olabe J, Roda J. Microsurgical cerebral aneurysm training porcine model. Neurol India. 2011 Jan-Feb;59(1):78-81. doi: org/10.4103/0028-3886.76872.

17. Borucki $€$, Szyfter W. Evaluation of an animal model in endoscopic surgery of the cerebello-pontine angle. Otolaryngol Pol. 2003;57(3):385-8. PubMed PMID: 14524182.

\section{Correspondence:}

Lucas Alves Aurich

Rua Jeremias Maciel Perretto, 300

81210-310 Curitiba - PR Brasil

Tel.: (55 11)3028-8552

aurich_lucas@yahoo.com.br

Received: Jan 16, 2014

Review: March 18, 2014

Accepted: April 22, 2014

Conflict of interest: none

Financial source: none

${ }^{1}$ Research performed at Laboratory of Microsurgery, Neurological Institute of Curitiba (INC), Curitiba-PR, Brazil. 